\title{
Bioinformatic Prediction of Novel Signaling Pathways of Apoptosis-inducing Factor, Mitochondrion-associated 3 (AIFM3) and Their Roles in Metastasis of Cholangiocarcinoma Cells
}

\author{
DARAPORN CHUA-ON ${ }^{1}$, TANAKORN PROUNGVITAYA ${ }^{1}$, ANCHALEE TECHASEN ${ }^{1,2}$, \\ TEMDUANG LIMPAIBOON ${ }^{1,2}$, SITTIRUK ROYTRAKUL ${ }^{3}$, \\ DOUNGDEAN TUMMANATSAKUN ${ }^{1}$, NORIE ARAKI ${ }^{4}$ and SIRIPORN PROUNGVITAYA ${ }^{1,2}$ \\ ${ }^{1}$ Centre of Research and Development of Medical Diagnostic Laboratories, \\ Faculty of Associated Medical Sciences, Khon Kaen University, Khon Kaen, Thailand; \\ ${ }^{2}$ Cholangiocarcinoma Research Institute, Faculty of Medicine, Khon Kaen University, Khon Kaen, Thailand; \\ ${ }^{3}$ Functional Ingredients and Food Innovation Research Group, \\ National Center for Genetic Engineering and Biotechnology, Pathumthani, Thailand; \\ ${ }^{4}$ Department of Tumor Genetics and Biology, Graduate School of Medical Sciences, \\ Kumamoto University, Kumamoto, Japan
}

\begin{abstract}
Background/Aim: We previously demonstrated that a mitochondrial protein, apoptosis-inducing factor, mitochondrion-associated 3 (AIFM3) is over-expressed in cholangiocarcinoma (CCA) and its serum levels can be a prognostic biomarker for CCA. To elucidate the functional roles of AIFM3 in CCA progression, we aimed to determine the signaling pathways of AIFM3 in CCA. Materials and Methods: AIFM3 gene in CCA cells was silenced and AIFM3related proteins were identified using mass spectrometry and bioinformatics tools. The relationships between AIFM3 and 441 related proteins were explored. To validate the functions of AIFM3, transwell migration/invasion assays were used. Results: Bioinformatic analyses predicted that AIFM3 interacts with formin-like protein 3 (FMNL3) and is involved in tumor cell motilities. Online database analysis revealed higher AIFM3 mRNA expression levels in CCA, particularly
\end{abstract}

This article is freely accessible online.

Correspondence to: Siriporn Proungvitaya, Ph.D., Associate Professor, Centre of Research and Development of Medical Diagnostic Laboratories, Faculty of Associated Medical Sciences, Khon Kaen University, 123 Mittraphap Road, Muang Khon Kaen, Khon Kaen 40002, Thailand. Tel: +66 43202088, e-mail: sirpat@kku.ac.th

Key Words: Cholangiocarcinoma, AIFM3, signaling pathway, bioinformatics, mass spectrometry, metastasis. with lymph node metastasis. After AIFM3 gene silencing, CCA cell migration/invasion was significantly decreased $(p<0.001)$. Furthermore, AIFM3 expression levels were significantly associated with lymph node metastasis $(p=0.0009)$ and shorter survival time $(p=0.020)$. Conclusion: The AIFM3 signaling pathway is mediated via FMNL3 and involved in metastasis, suggesting that AIFM3 might be a molecular target to prevent CCA metastasis.

Cholangiocarcinoma (CCA) is a malignant tumor originating from the epithelium of bile ducts (1). Globally, CCA is rather a rare cancer, but its incidence is extremely high in the Greater Mekong Subregion of Southeast Asia due to the carcinogenic liver fluke (Opisthorchis viverrini) infection caused by consumption of raw or undercooked fish contaminated with metacercaria (infective stage). Because of the poor survival rate, $\mathrm{CCA}$ is a serious health problem in the northeastern part of Thailand (2). The best treatment method is surgical resection, but most patients with CCA are usually diagnosed at the late stage of the disease (1). After surgery, patients with late stage CCA are usually treated with chemotherapeutic drugs such as cisplatin, 5-fluorouracil, gemcitabine, and doxorubicin (3). However, currently there is no method to improve the survival of patients with CCA. To enhance the efficacy of cancer treatment, earlier diagnosis and development of targeted cancer therapy are required (4).

Mitochondrial proteins are known to play critical roles in tumor development/progression of various cancers (5-7). 
Recent biomarker search revealed that several mitochondrial proteins are detectable in the plasma and their over-expression is considered as potential biomarkers for diagnosis/prognosis of certain cancers $(8,9)$. Also, mitochondrial proteins are considered as targets for cancer therapy (7).

AIFM3 is a mitochondrial protein that consists of 598 amino acids, with a molecular weight of $66 \mathrm{kDa}(10)$. AIFM3 has $35 \%$ similarity with the sequence of the apoptosis-inducing factor (AIF). Similarly, AIFM3 has the ability to induce apoptosis $(10,11)$. Nonetheless, analysis of mitochondrial proteome indicated that AIFM3 was overexpressed in CCA tissues in comparison with the matched adjacent non-cancerous tissues (12). Subsequently, we reported that higher serum AIFM3 levels were significantly associated with lymph node metastasis and shorter overall survival of patients with CCA, and AIFM3 could be an independent prognostic marker for patients with CCA (13). In this study, to elucidate the possible role of AIFM3 and the related signaling pathways in CCA cells, we used a combination of gene-silencing, mass spectrometry, and bioinformatic tools. Furthermore, using CCA cells, we examined the effects of AIFM3 gene knock-down on tumor cell motilities by migration-invasion assays. Moreover, AIFM3 expression levels in surgical specimens were used to validate its diagnostic/prognostic role.

\section{Materials and Methods}

Cell lines and cell culture. Four CCA cell lines were used; KKU213A and KKU-213B (intrahepatic CCA) were kindly provided by the Japanese Collection of Research Bioresources (JCRB) Cell Bank (Osaka, Japan), KKU-100 (extrahepatic/perihilar CCA) (14) and KKU-452 (perihilar and intrahepatic mass-forming CCA) (15) were kindly provided by the Cholangiocarcinoma Research Institute (CARI) (Khon Kaen University, Thailand). Additionally, MMNK-1 was generated by Maruyama et al. (16). Cell lines were cultured in Ham's F-12 medium containing 10\% fetal bovine serum, $100 \mathrm{U} / \mathrm{ml}$ of penicillin and $100 \mu \mathrm{g} / \mathrm{ml}$ of streptomycin (all from Life technologies, Grand Island, NY, USA) in a humidified $5 \% \mathrm{CO}_{2}$ air incubator at $37^{\circ} \mathrm{C}$. All cell lines were verified to be mycoplasma-free using specific PCR.

Tissue samples. Paraffin-embedded sections of 24 CCA patients were provided by CARI, Khon Kaen University. The patients who underwent surgery at the Srinagarind Hospital, Khon Kaen University (2009-2012) were enrolled. In accordance with the pathological reports, 8 of 24 patients presented with lymph node metastasis. The present study was approved by the Human Ethics Committee of Khon Kaen University (approval No. HE611411) and informed consent was obtained from all participants.

Western blot analysis. To investigate the expression of AIFM3 protein, the cells were harvested and lysed in RIPA lysis buffer as previously described (17). The protein concentration was determined using the Bradford assay. The expression of AIFM3 was validated using western blot analysis. Western blotting was performed as described previously with some modifications (12). Three independent experiments were performed to confirm reproducibility. In brief, $30 \mu \mathrm{g}$ protein of each cell lysate was dissolved in sample buffer and boiled for $5 \mathrm{~min}$. The samples were loaded and separated on $12.5 \%$ SDS-PAGE for $3 \mathrm{~h}$, and the proteins were transferred onto PVDF membrane (GE Healthcare, Buckinghamshire, UK). The membrane was incubated with 1:500 dilution of rabbit polyclonal antibody against human AIFM3 (Biorbyt, Cambridge, UK) overnight at $4^{\circ} \mathrm{C}$. Peroxidase activity was detected and quantitatively analyzed using an Amersham Imager 600. Densitometry of different immunoblots was measured using ImageJ software (version. $1.52 \mathrm{v}, \mathrm{NIH}$, Bethesda, MD, USA) and normalized relative to actin expression.

Transient silencing of AIFM3 gene using siRNA. High AIFM3 expressing cell lines, KKU-213A and KKU-213B, were selected for gene silencing. To silence AIFM3 gene, $1.5 \times 10^{5}$ cells/well of KKU213A and KKU-213B cells were seeded on six-well plates and incubated overnight before transfection with $100 \mathrm{pM}$ of siAIFM3 (Santa Cruz Biotechnology, Santa Cruz, CA, USA) and scramble negative control (Invitrogen, Carlsbad, CA, USA) using Lipofectamine 2000 (Invitrogen) following the manufacturer's instructions. Six hours after transfection, culture medium was replaced with fresh complete medium and incubated at $37^{\circ} \mathrm{C}$ for 24 and $48 \mathrm{~h}$. To verify suppression of AIFM3 expression, the cells were harvested into RIPA lysis buffer and western blotting was performed.

Gel formation and tryptic digestion. AIFM3-silenced and scramble control of KKU-213A and KKU-213B cells were lysed $24 \mathrm{~h}$ after transfection, and their protein concentration was determined by the Bradford assay. For tryptic digestion, $5 \mu \mathrm{g}$ each of cell lysate was mixed with acrylamide and the resulting gel was cut into small pieces. In-gel tryptic digestion and peptide extraction were performed as reported previously (17) using an in-house method developed by Proteomics Laboratory, National Center for Genetic Engineering and Biotechnology, National Science and Technology Development Agency, Thailand.

Liquid chromatography-tandem mass spectrometry (LC-MS/MS) and protein identification. The extracted peptides were resuspended in $20 \mu \mathrm{l}$ of $0.1 \%$ formic acid, centrifuged at $10,000 \times \mathrm{g}$ for $10 \mathrm{~min}$ before loading into LC-MS/MS system. The LC-MS/MS analysis and protein identification were performed as previously described in detail (17).

Selection of candidate proteins using bioinformatic tool. The efficiency of AIFM3 silencing was derived from mass spectrometric signal intensity of AIFM3-silenced and scramble-treated KKU-213A and KKU-213B cells. Thus, all proteins of the cell lysates of AIFM3-silenced and scramble-treated KKU-213A and KKU-213B cells were categorized using jvenn (18). Afterwards, to determine the possible signaling pathway of AIFM3 in CCA, proteins that were commonly expressed in scramble-treated KKU-213A and KKU-213B cells, but not in siRNA-treated cells, were chosen as the candidate protein group.

Prediction of AIFM3-related signaling pathway. Potential interaction of the AIFM3 with related proteins was predicted using STITCH 5.0 (19). A final list of proteins associated with a high confidence score of $>0.7$ was obtained, which suggested a high confidence score according to STITCH (20). 
A

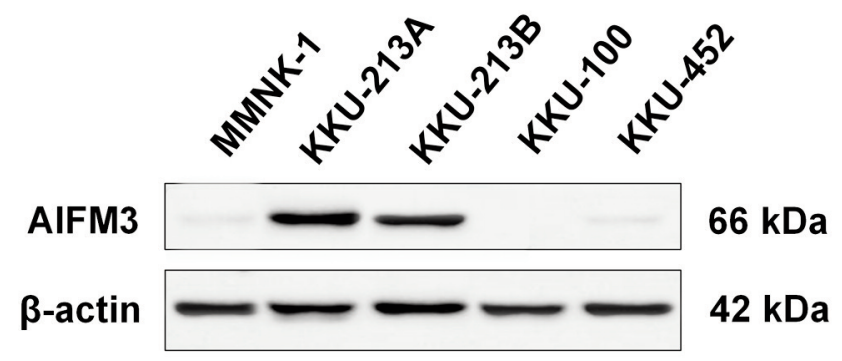

B

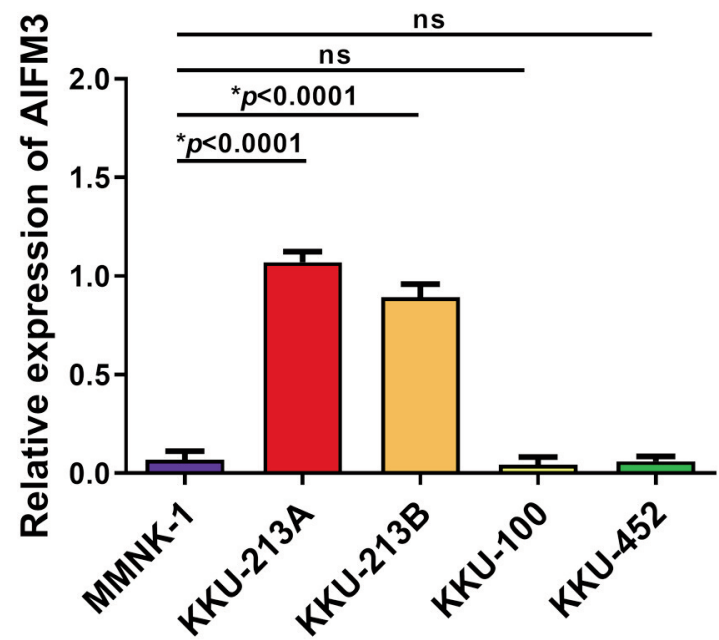

Figure 1. Expression of apoptosis-inducing factor, mitochondrion-associated 3 (AIFM3) in cholangiocarcinoma (CCA) and immortalized cholangiocyte cell lines. (A) Western blot analysis shows high expression of AIFM3 in KKU-213A and KKU-213B. $\beta$-actin was used as a control for protein loading. (B) AIFM3 protein expression was determined using image-quantitative analysis. The ratio of AIFM 3 and $\beta$-actin intensity is shown as relative expression of AIFM3. Values are expressed as the mean $\pm S D$ from three independent experiments running in triplicate. $*$ Significant difference of AIFM3 expression among cell lines compared to MMNK-1; ns: no significant difference.

Prediction of interaction of AIFM3-FMNL3 and chemotherapeutic drugs. Interaction between AIFM3-FMNL3 and chemotherapeutic drugs was analyzed using STITCH 5.0 as described above.

Molecular docking. CB-Dock (21) was used to predict the binding activities of proteins to compounds and estimate the center and size of the cavity. It was also combined with AutoDock Vina in which binding affinity prediction was set at $70 \%$ success rate (21). The lowest Vina score and the largest cavity size predict strong binding interaction (21). The file formats of the protein database (PDB) and ligand were obtained from the PDB and PubChem, respectively (22). The docking of AIFM3 and FMNL3, AIFM3 and magnesium adenosine triphosphate (MgATP), and FMNL3 and MgATP was ranked. The three-dimensional (3D) X-ray crystal structure of human AIFM3 (PDB ID: 6SK8, solution $1.8 \AA$ ) and FMNL3 (PDB ID: 4EAH, solution $3.4 \AA$ ) were searched from the Protein Data Bank. The structure of MgATP (Compound CID: 15126) was obtained from PubChem.

Verification of AIFM3 expression in patients with CCA. To verify the mRNA expression levels of AIFM3 in CCA and normal tissues, the data sets were retrieved and analyzed using Gene Expression Profiling Interactive Analysis 2 (GEPIA2) (23) and the open access database UALCAN (24). The differences in the mRNA expression levels of AIFM3 and related molecules in CCA and normal tissues were validated on the GEPIA2 platform using the Spearman correlation method (23).

Cell migration and invasion assay. After $12 \mathrm{~h}$ of transfection, the effect of AIFM3-silencing on cell motility was examined using a Transwell migration/invasion assay as described previously (17).
Immunohistochemistry. Expression of AIFM3 in CCA tissues was evaluated using immunohistochemical staining as described previously (12).

Statistical analysis. Experiments were performed in triplicate. Data values are presented as mean \pm standard deviation $(\mathrm{SD})$ and the median and interquartile range. Comparison of parametric data was performed by $t$-test, whereas non-parametric groups were analysed using the Mann-Whitney $U$-test. Overall survival was estimated using KaplanMeier analysis. All statistical analyses were performed using GraphPad Prism software (version 8; GraphPad Software Inc., La Jolla, CA, USA) and SPSS software (version 20; SPSS, Inc., IBM, NY, USA). The $p$-value $<0.05$ was considered statistically significant.

\section{Results}

Expression of AIFM3 in cell lines. AIFM3 protein expression levels of four CCA cell lines, KKU-213A, KKU-213B, KKU-100, and KKU-452 and an immortalized cholangiocyte cell line, MMNK-1, were determined using western blot analysis. AIFM3 protein was highly expressed in KKU-213A and KKU-213B cell lines (Figure $1 \mathrm{~A}$ and $\mathrm{B}$ ), but not in KKU-100 and KKU-452 cell lines. Accordingly, we selected KKU-213A and KKU-213B cell lines for further analyses.

AIFM3 gene silencing of CCA cell lines. To investigate the biological roles of AIFM3 in CCA cells, AIFM3 gene in KKU-213A and KKU-213B cells was silenced using siRNA. AIFM3 protein expression of KKU-M213A and KKU- 
A

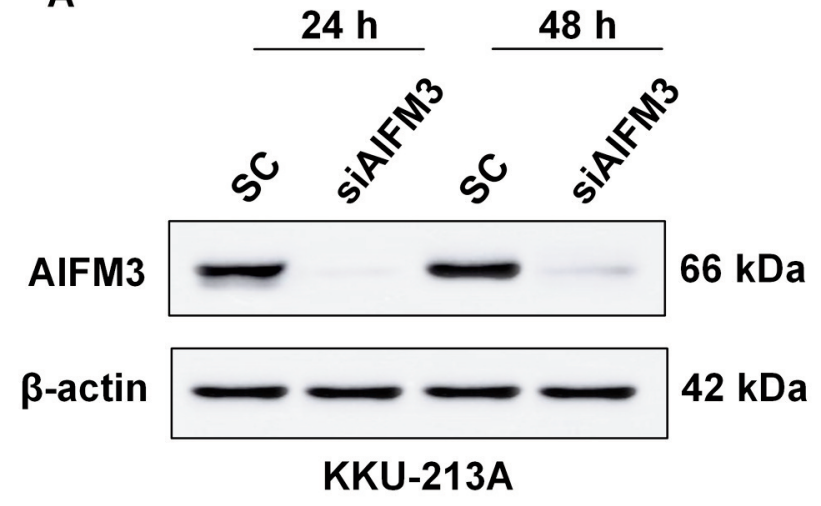

C

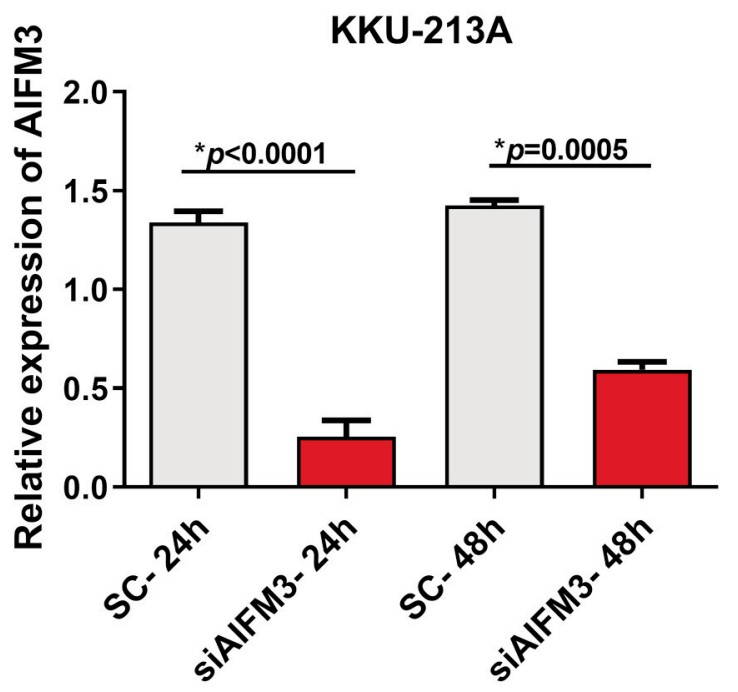

B

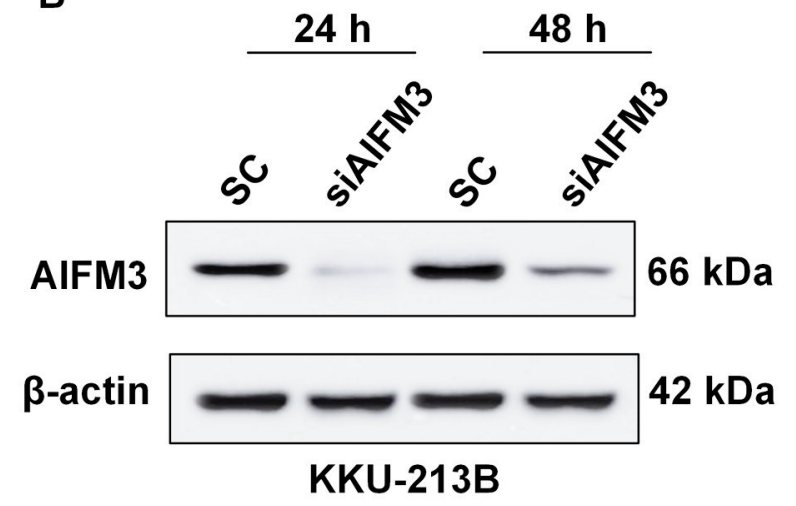

D

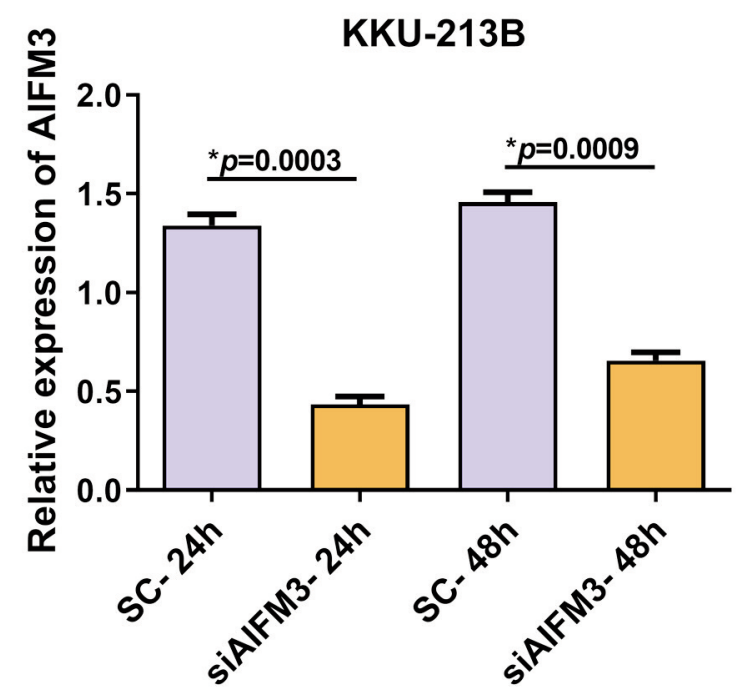

Figure 2. Expression of apoptosis-inducing factor, mitochondrion-associated 3 (AIFM3) protein in AIFM3 gene-silenced and scramble-control cholangiocarcinoma (CCA) cell lines. The cells treated with nonspecific siRNA (scramble, SC) were used as controls. $\beta$-actin protein expression was used as an internal control. (A) Western blotting shows AIFM3 protein levels in the cell lysates of siRNA-treated and scramble-treated KKU$213 A$ and $(B) K K U-213 B$ cell lines. (C) The intensities of AIFM3 expression levels siRNA-treated KKU-213A and (D) KKU-213B cells were quantitatively analyzed and expressed as relative expression of AIFM3 at each time point. Values are expressed as the mean $\pm S D$ from three independent experiments running in triplicate. Statistically significantly different compared to scramble control. *Significant difference of AIFM3 expression between time points.

M213B cells was successfully suppressed compared with siRNA scramble control at $24 \mathrm{~h}$ and $48 \mathrm{~h}$ after silencing (Figure 2A-D). These results showed that the AIFM3 silencing effect was higher at $24 \mathrm{~h}$ than $48 \mathrm{~h}$. Thus, protein identification using mass spectrometry was performed at 24 $\mathrm{h}$ after AIFM3 silencing.

Mass spectrometric protein expression patterns of AIFM3gene-silenced and scramble-treated $K K U-213 \mathrm{~A}$ and $K K U$ $213 \mathrm{~B}$ cell lines. To determine the roles of AIFM3 and its signaling pathways in CCA, mass spectrometric protein expression patterns of AIFM3 gene-silenced and scrambletreated KKU-213A and KKU-213B cell lines were analyzed using Venn diagram. As shown in Figure 3, regardless of siRNA-treated or scramble-treated, KKU-213A and KKU213B cells expressed about 3,000 proteins (Figure 3A). Using jvenn, 441 proteins were commonly expressed in scramble-treated KKU-213A and KKU-213B cells but not in AIFM3-gene-silenced cells (Figure 3B). Those 441 proteins were selected for further bioinformatic analysis to predict potential proteins related to AIFM3 function using STITCH (Figure 3C). 
A

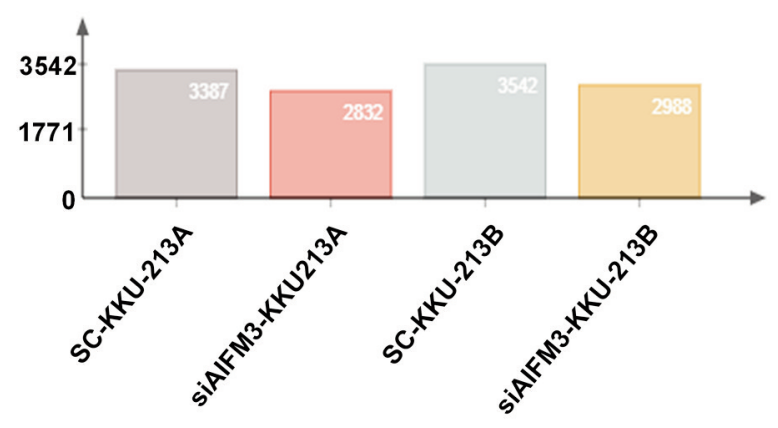

C
B

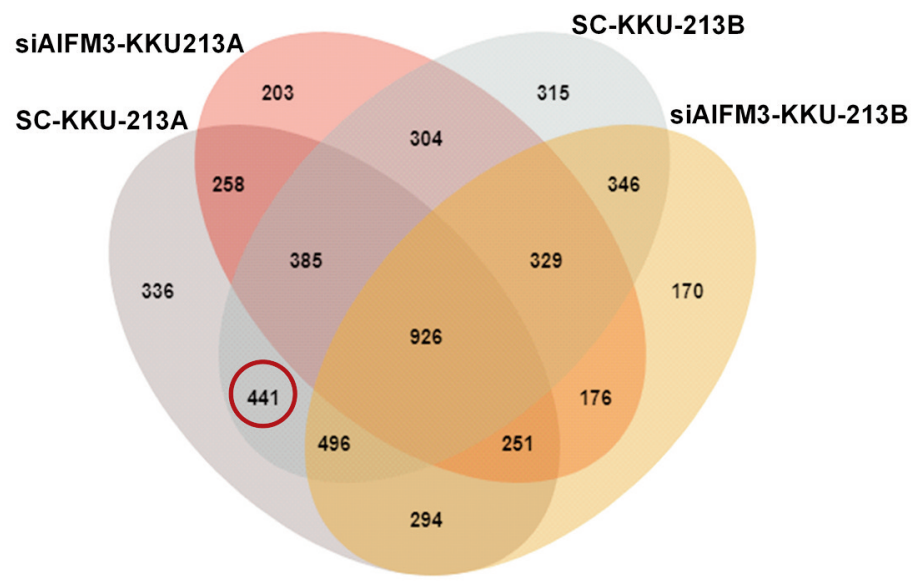

441 proteins were predicted the possible signaling pathways using STITCH

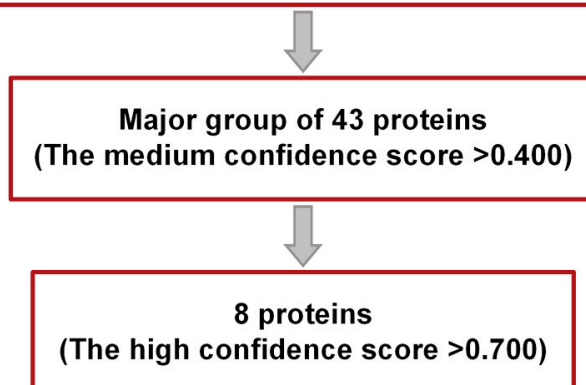

Figure 3. Identification of AIFM3-related proteins. (A) Total number of proteins in each sample. (B) Venn diagram showing the degree of overlapping among proteins of AIFM3-gene silenced and scramble-treated KKU-213A and KKU-213B cells. The number in the red circle represents the candidate proteins. (C) Flowchart of the selection of AIFM3-related proteins in scramble-treated CCA cells.

Prediction of the signaling pathways related to AIFM3. The selected 441 proteins commonly expressed in scrambletreated KKU-213A and KKU213B cells were analyzed to predict the AIFM3-related signaling pathway using STITCH version 5.0. Interactions with a medium confidence score $>0.4$ between AIFM3 and related proteins revealed many possible signaling pathways, but the major AIFM3-related proteins were only 43 proteins (Figure $4 \mathrm{~A}$ and Table I). Among these 43 proteins, 8 with a high confidence score of $>0.7$ are involved in migration and metastatic pathways; formin-like protein 3 (FMNL3), phosphatidylinositol-4,5bisphosphate 3-kinase catalytic subunit alpha (PIK3CA or PI3K), RAC-beta serine/threonine-protein kinase (AKT2), zinc finger protein SNAI1 (SNAIL1), nuclear factor kappa B subunit 1 (NFKB1), matrix metallopeptidase 2 (MMP2) and matrix metallopeptidase 7 (MMP7). Based on STITCH analysis, AIFM3 was directly associated with FMNL3, a potential biomarker for cell migration, and indirectly with PIK3CA, AKT2, SNAIL1, NFKB1, MMP2 and MMP7, protein markers related to cell migration, invasion and metastasis of tumor cells. To validate the correlation between mRNA expression levels of AIFM3 and those of the other proteins in AIFM3-related metastatic pathways, we further performed GEPIA2 analysis. AIFM3 mRNA levels were significantly correlated with those of FMNL3 $(p=0.048)$ (Figure 4B) but not with those of the other proteins.

To elucidate whether AIFM3 and FMNL3 can be potential molecular targets for cancer chemotherapy, we predicted the networks of protein-chemotherapy drug interactions using STITCH. The results showed the association of both AIFM3 and FMNL3 with cisplatin, doxorubicin, 5-fluorouracil, and gemcitabine via MgATP (Figure 4C). Particularly, higher confidence of association was observed between MgATP and cisplatin and also doxorubicin.

Besides, the mRNA level of FMNL3 was significantly correlated with that of PIK3CA, SNAIL1, NFKB,1 and MMP2 $(\mathrm{R}=0.54, p=0.0008, \mathrm{R}=0.48 p=0.0033, \mathrm{R}=0.67, p<0.0001$, and $\mathrm{R}=0.71, p<0.0001$, respectively) (Figure 5A-D). 


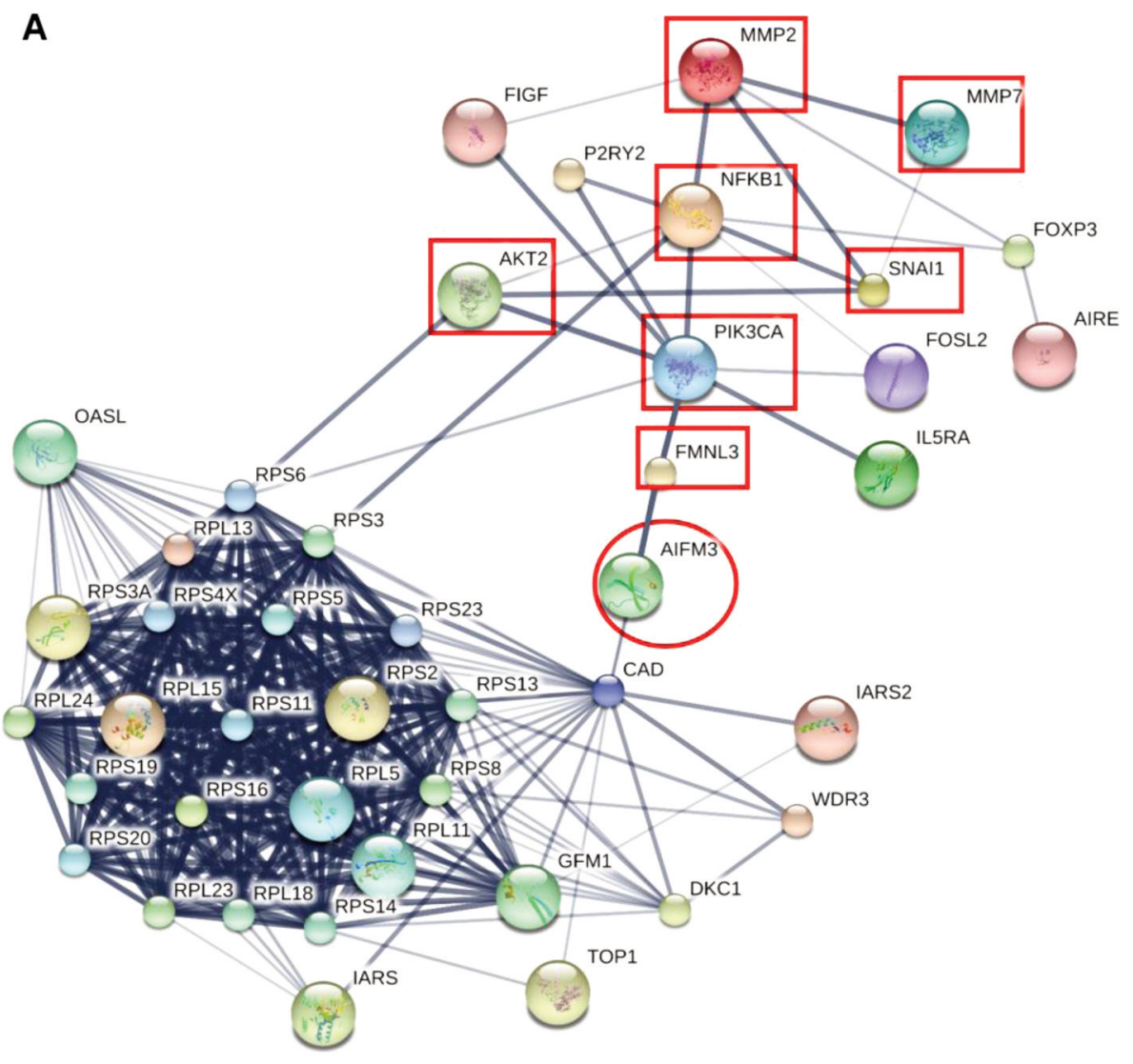

B

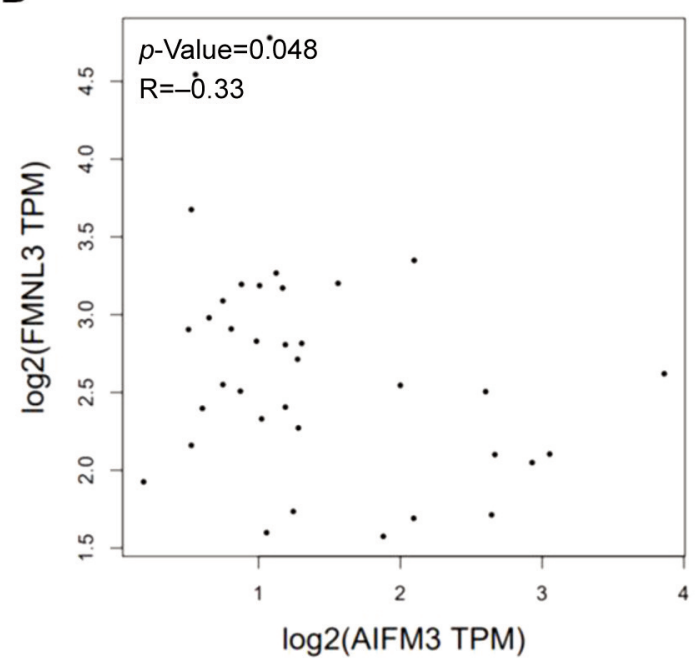

C

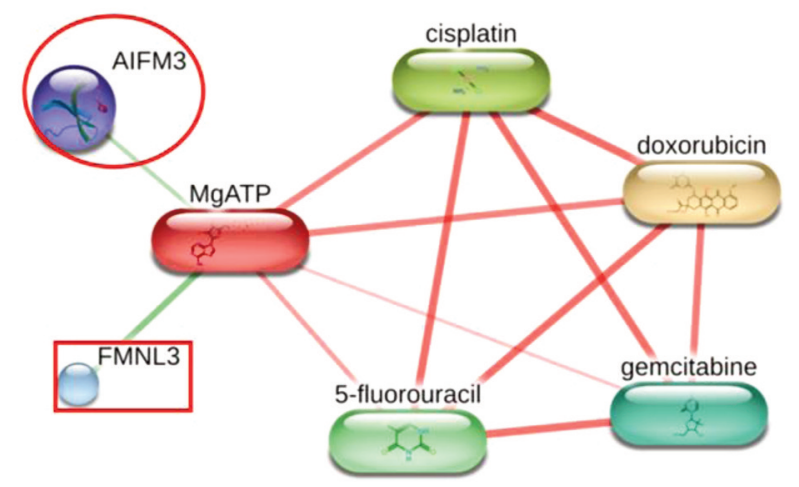

Figure 4. Potential interaction of apoptosis-inducing factor, mitochondrion-associated 3 (AIFM3)-related proteins expressed in scramble-treated but not siRNA-treated KKU-213A and KKU-213B cells. (A) The major interaction of AIFM3 (in red circle) is associated with migratory and/or metastatic protein markers: Formin-like protein 3 (FMNL3), phosphatidylinositol-4,5-bisphosphate 3-kinase catalytic subunit alpha (PIK3CA), RAC- beta serinelthreonine-protein kinase (AKT2), zinc finger protein SNAI1 (SNAIL1), nuclear factor kappa B subunit 1 (NFKB1), matrix metallopeptidase 2 (MMP2) and 7 (MMP7) (in red box). Stronger associations are represented by thicker lines. Weak associations are represented by thin lines. Protein-protein interactions are shown in grey, chemical-protein interactions in green and interactions between chemicals in red lines. (B) Gene Expression Profiling Interactive Analysis 2 (GEPIA2) analysis of RNA expression correlation between AIFM3 and FMNL3. (C) Predicted interaction of AIFM3 (in red circle) and FMNL3 (in red box) with chemotherapeutic drugs, cisplatin, 5-fluorouracil, gemcitabine, and doxorubicin. 
Table I. The list of 43 proteins uniquely expressed in scramble-treated CCA cell lines.

\begin{tabular}{|c|c|}
\hline Protein name & Gene name \\
\hline Apoptosis-inducing factor, mitochondrion-associated 3 & AIFM3 \\
\hline Autoimmune regulator & AIRE \\
\hline Carbamoyl-phosphate synthetase 2 , aspartate transcarbamylase, and dihydroorotase & $C A D$ \\
\hline C-fos induced growth factor & $F I G F$ \\
\hline Dyskeratosis congenita 1 , dyskerin & $D K C 1$ \\
\hline Formin-like protein 3 & FMNL3 \\
\hline FOS-like antigen 2 & FOSL2 \\
\hline Forkhead box P3 & FOXP3 \\
\hline G elongation factor, mitochondrial 1 & GFM1 \\
\hline Interleukin 5 receptor, alpha & ILSRA \\
\hline Isoleucyl-tRNA synthetase 2 , mitochondrial & IARS2 \\
\hline Isoleucyl-tRNA synthetase & IARS \\
\hline Matrix metallopeptidase 2 & $M M P 2$ \\
\hline Matrix metallopeptidase 7 & $M M P 7$ \\
\hline Nuclear factor kappa B subunit 1 & $N F K B 1$ \\
\hline Oligoadenylate synthetase-like & $O A S L$ \\
\hline Phosphatidylinositol-4,5-bisphosphate 3-kinase, catalytic subunit alpha & $P I K 3 C A$ \\
\hline Purinergic receptor P2Y, G-protein coupled, 2 & $P 2 R Y 2$ \\
\hline Ribosomal protein L18 & RPL18 \\
\hline Ribosomal protein L15 & RPL15 \\
\hline Ribosomal protein L13 & RPL13 \\
\hline Ribosomal protein L11 & RPL11 \\
\hline Ribosomal protein L23 & RPL23 \\
\hline Ribosomal protein L24 & RPL24 \\
\hline Ribosomal protein $\mathrm{S} 2$ & RPS2 \\
\hline Ribosomal protein S4 & RPS4 \\
\hline Ribosomal protein S5 & RPS5 \\
\hline Ribosomal protein S6 & RPS6 \\
\hline Ribosomal protein $\mathrm{S} 3$ & RPS3 \\
\hline Ribosomal protein S3A & RPS3A \\
\hline Ribosomal protein S8 & RPS8 \\
\hline Ribosomal protein $\mathrm{S} 11$ & RPS11 \\
\hline Ribosomal protein $\mathrm{S} 13$ & RPS13 \\
\hline Ribosomal protein $\mathrm{S} 14$ & RPS14 \\
\hline Ribosomal protein $\mathrm{S} 4, \mathrm{X}$-linked & $R P S 4 X$ \\
\hline Ribosomal protein S16 & RPS16 \\
\hline Ribosomal protein S19 & RPS19 \\
\hline Ribosomal protein $\mathrm{S} 20$ & RPS20 \\
\hline Ribosomal protein $\mathrm{S} 23$ & RPS23 \\
\hline Zinc finger protein SNAI1 & SNAIL1 \\
\hline Topoisomerase 1 & TOP1 \\
\hline RAC- beta serine/threonine-protein kinase & AKT2 \\
\hline WD repeat domain 3 WDR 3 & WDR3 \\
\hline
\end{tabular}

Molecular docking of ligand-target among AIFM3, FMNL3 and MgATP. To assess the binding of AIFM3 and FMNL3 predicted by STITCH, the binding activities of proteins to ligands and the size of the cavity were explored using CBDock. After docking analysis, AIFM3 had probability to bind FMNL3 with a range of binding energy Vina score $(-6.5)$ $(-8.2) \mathrm{kcal} / \mathrm{mol}$ and a cavity size of $418-15,190$. The degree of negativity of the Vina score represents the degree of stable binding between the ligand and the target, and the larger the cavity size the closer the distance between the ligand and the target. Docking accuracy increases as the Vina score decreases and the cavity size increases (21). Molecular docking results showed that AIFM3 had a binding activity for FMNL3 with the Vina scores of $-8.2 \mathrm{kcal} / \mathrm{mol}$ and a cavity size of 15,190 (Figure 6A).

To evaluate whether AIFM3-FMNL2 had probability to bind the MgATP compound, we ranked molecular docking between AIFM3 and MgATP, and also FMNL3 and MgATP. Molecular docking between AIFM3 and MgATP showed a binding energy Vina score in the range of $(-6.4)$ 
A

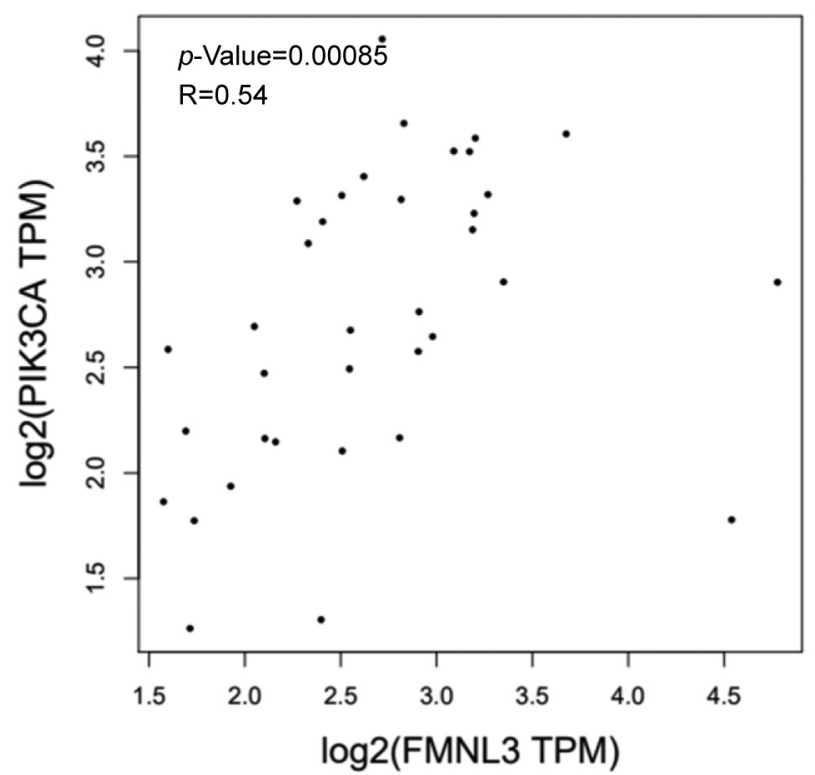

C

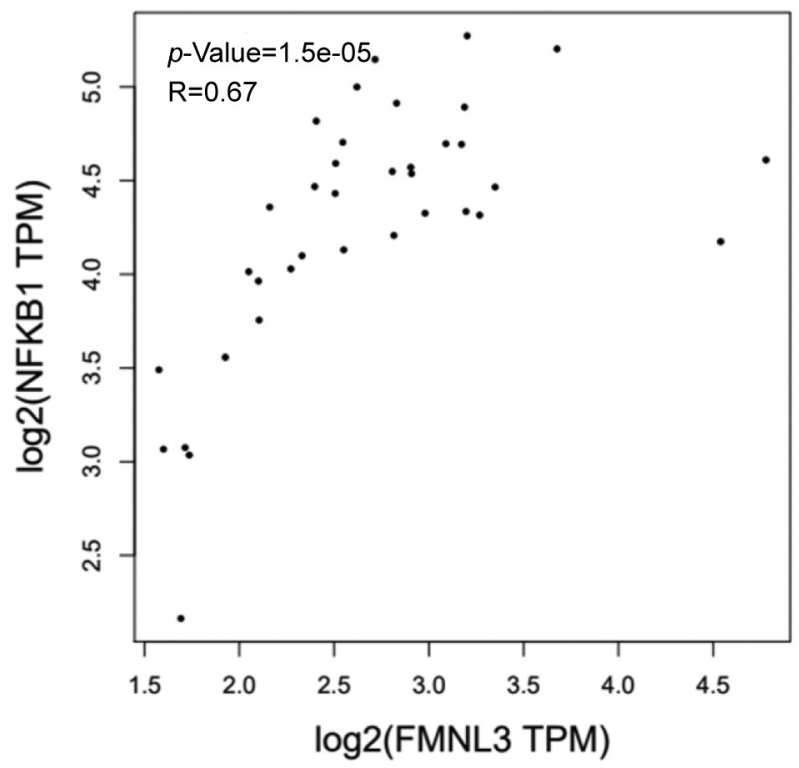

B

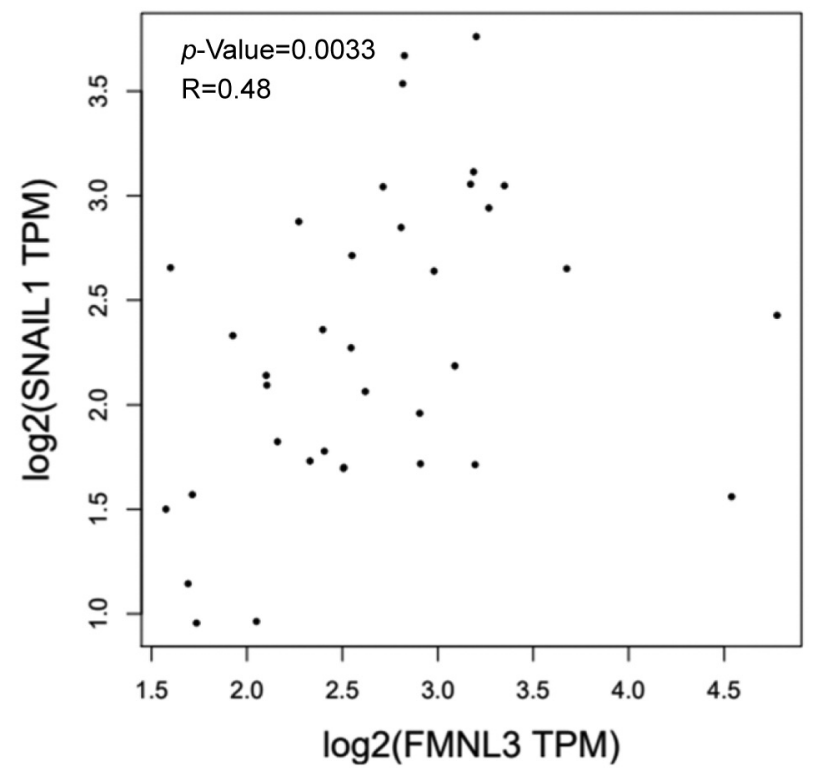

D

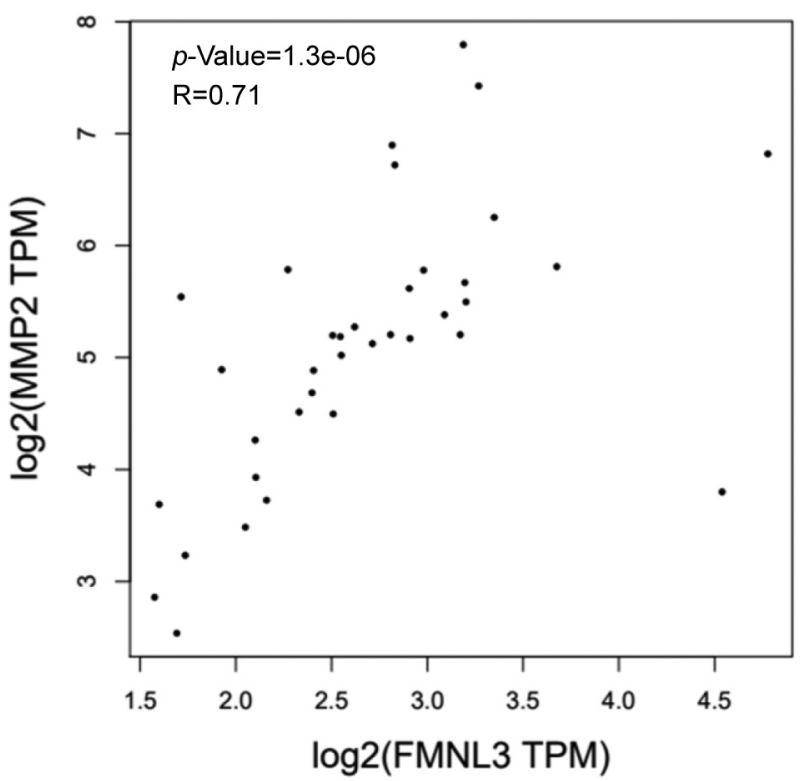

Figure 5. Correlation of mRNA expression levels between formin-like protein 3 (FMNL3) and phosphatidylinositol-4,5-bisphosphate 3-kinase catalytic subunit alpha (PIK3CA), zinc finger protein SNAI1 (SNAIL1), nuclear factor kappa B subunit 1 (NFKB1) or matrix metallopeptidase 2 (MMP2) analyzed with Gene Expression Profiling Interactive Analysis 2 (GEPIA2) tool. (A) Between FMNL3 and PIK3CA, (B) between FMNL3 and SNAIL1, (C) between FMNL3 and NFKB1, and (D) between FMNL3 and MMP2. Data were retrieved from GEPIA2 tool as log2 of transcript per million $(T P M)$ and analyzed by Spearman correlation method. Statistically significant at $p<0.01, p<0.001$ and $p<0.0001$.

- (-9.4) $\mathrm{kcal} / \mathrm{mol}$ and cavity size $354-14,192$. Therefore, AIFM3 has strong binding to MgATP with Vina score -9.4 $\mathrm{kcal} / \mathrm{mol}$ and cavity size 14,192 (Figure 6B). Moreover, FMNL3 and MgATP showed binding energy Vina score in the range of $(-6.9)-(-10.3) \mathrm{kcal} / \mathrm{mol}$ and cavity size $526-$
17,170. Thus, FMNL3 had strong binding to MgATP with Vina score $-10.3 \mathrm{kcal} / \mathrm{mol}$ and cavity size 17,170 (Figure 6C). These results were similar to those obtained with STITCH. Thus, AIFM3 possibly interacts with FMNL3 via MgATP. 

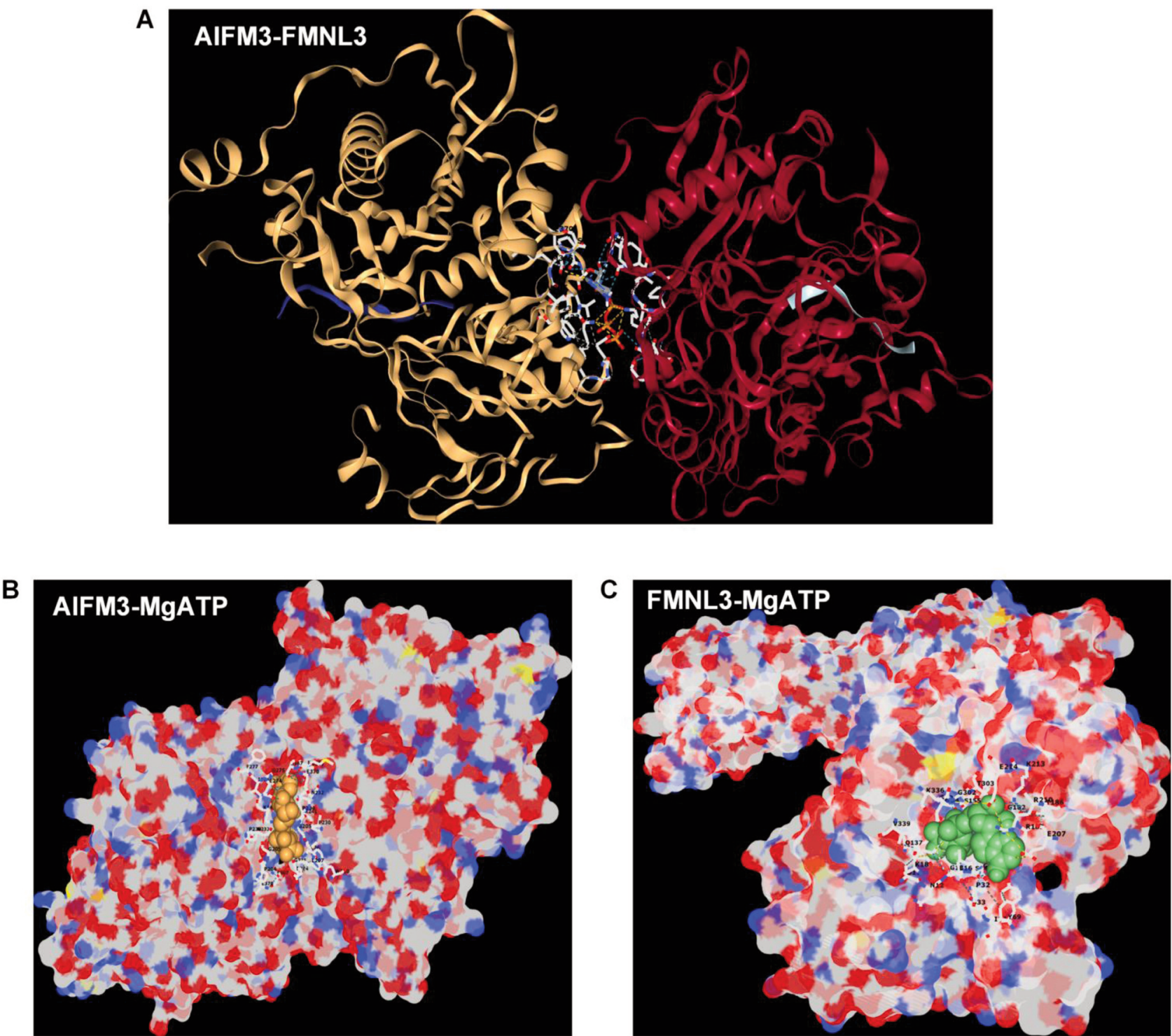

Figure 6. Cartoon representation of ligand and protein structures with their pocket binding sites. (A) The probability of binding between apoptosisinducing factor, mitochondrion-associated 3 (AIFM3) and formin-like protein 3 (FMNL3). Gold ribbon represents FMNL3 protein, red ribbon represents AIFM3 protein and sticks represent interaction bonds. (B) The probability of binding between AIFM3 and magnesium adenosine triphosphate (MgATP). The cartoon represents AIFM3 protein. The MgATP at the appropiate position is shown as gold spheres. (C) The probability of binding between FMNL3 and MgATP. The cartoon represents FMNL3 protein. The MgATP at the appropiate position is shown as green spheres.

Aberrant expression of AIFM3 $\mathrm{mRNA}$ in patients with CCA To access further the possible importance of AIFM3 in CCA, mRNA expression levels between CCA and normal tissues were analyzed using TCGA databases on GEPIA2 and ULCAN ( 9 normal and 36 cancerous samples). The results of GEPIA2 and UALCAN showed significantly higher AIFM3 mRNA expression levels in CCA than in normal samples $(p<0.0001)$ (Figure 7A and B). To explore the association between clinicopathological parameters with AIFM3 expression levels, stratified analysis was performed based on tumor grading and metastasis status. As shown in Figure 7C, AIFM3 expression was significantly higher in patients with CCA and tumor grade II-IV $(p<0.0001)$, in particular, in lymph node metastatic CCA $(p<0.0001)$ (Figure 7D).

Effect of AIFM3 gene silencing on cell migration and invasion activity of $K K U-213 A$ and $K K U-213 B$ cell lines. Since FMNL3, a protein marker for cell migration and 
A

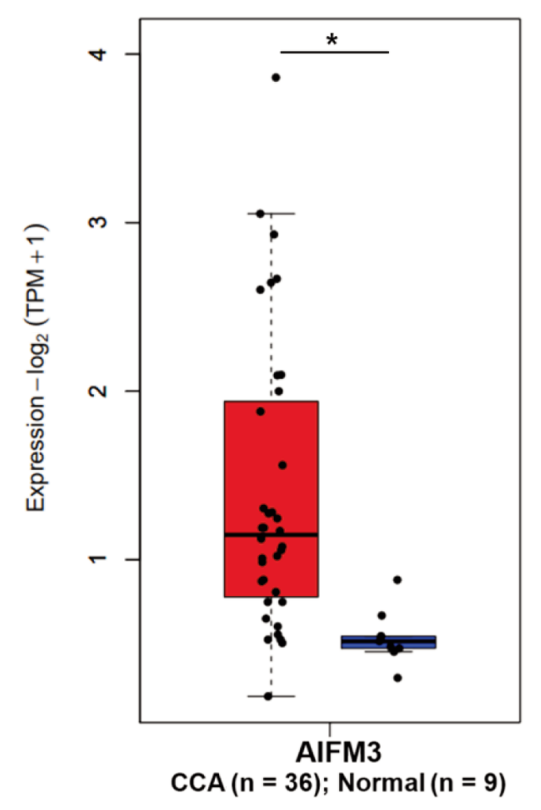

B

\section{Expression of AIFM3 in CCA based on Sample types}

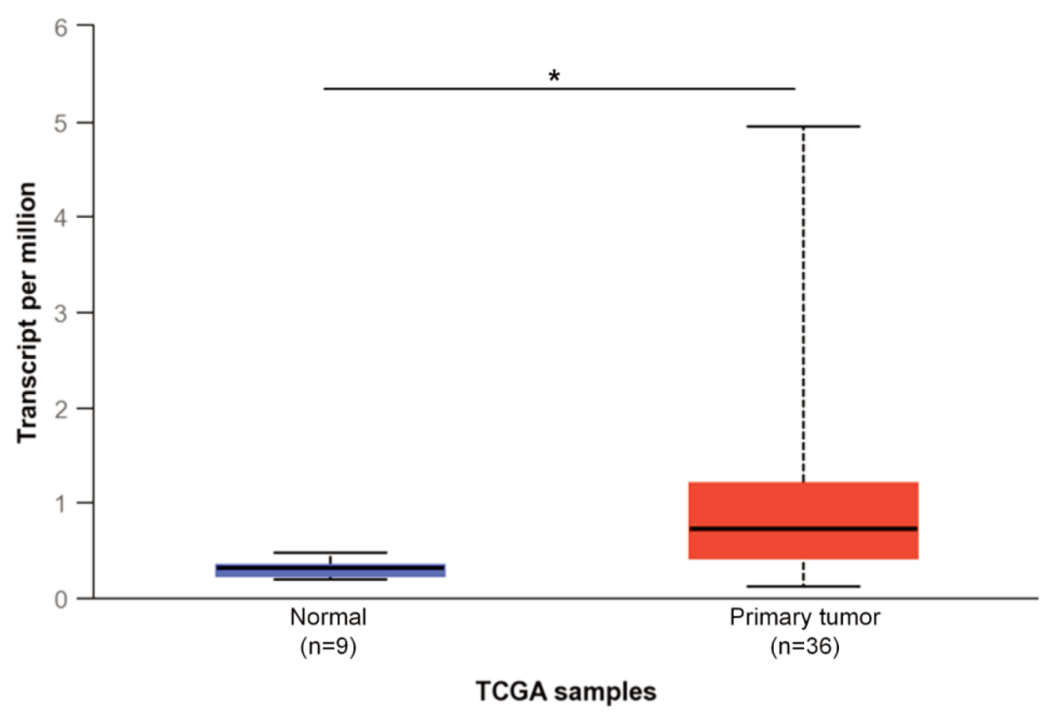

C

\section{Expression of AIFM3 in CCA based on tumor grade}

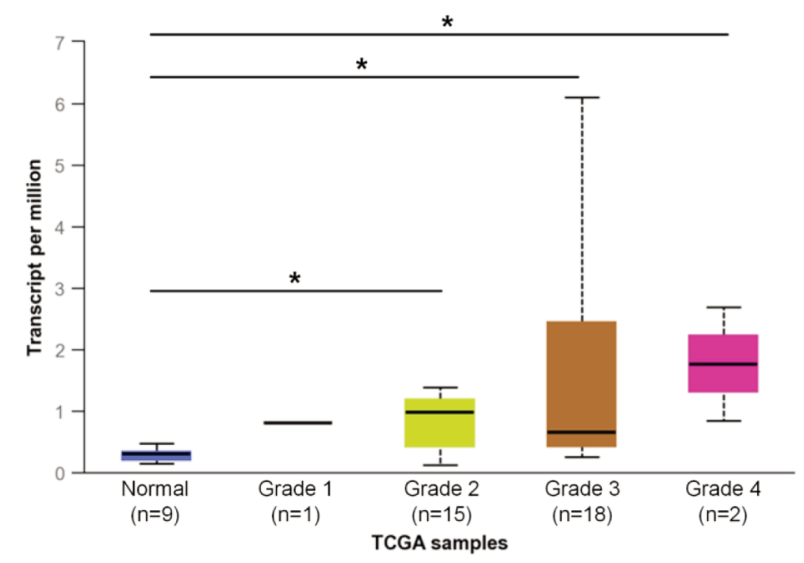

D

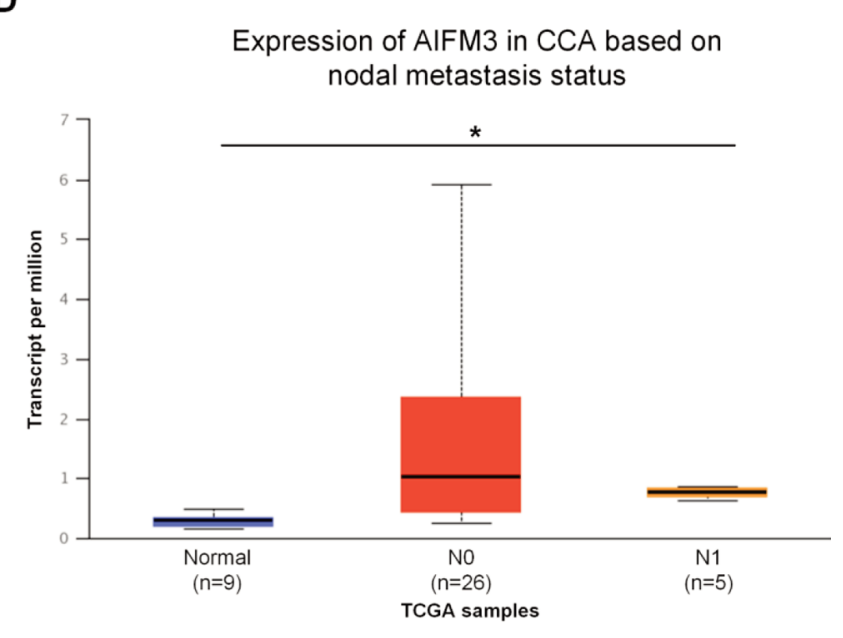

Figure 7. The apoptosis-inducing factor, mitochondrion-associated 3 (AIFM3) mRNA expression levels in cholangiocarcinoma (CCA) and normal tissues retrieved from Gene Expression Profiling Interactive Analysis 2 (GEPIA2) and ULCAN. (A) GEPIA2 analysis of mRNA expression levels of AIFM3 in patients with CCA. (B) ULCAN analysis of mRNA expression levels of AIFM3. (C-D) The different expression levels of AIFM3 based on tumor grading and metastasis status were explored in patients with CCA using UALCAN website. Grade 1: Well differentiated (low grade), Grade 2: Moderately differentiated (intermediate grade), Grade 3: Poorly differentiated (high grade), Grade 4: Undifferentiated (high grade); N0: No regional lymph node metastasis, N1: Metastases in 1 to 3 axillary lymph nodes. Transcript per million (TPM) values are presented as the median and interquartile range and estimated the significance of difference in mRNA expression levels between groups. The t test was performed using a PERL script with Comprehensive Perl Archive Network (CPAN) module. *Statistically significant $(p<0.0001)$.

invasion, is likely to be located directly downstream of AIFM3, and over-expressed in patients with CCA with lymph node metastasis, we assessed the role of AIFM3 in the motility of CCA cells. For this purpose, the effects of AIFM3-gene silencing on the motility of KKU-213A and
KKU213B cells were examined using cell migration and invasion assays. As shown in Figure 8, suppression of AIFM3 expression caused significant reduction in the number of migrated cells compared to the corresponding scramble controls in both KKU-213A and KKU-213B cells 
A

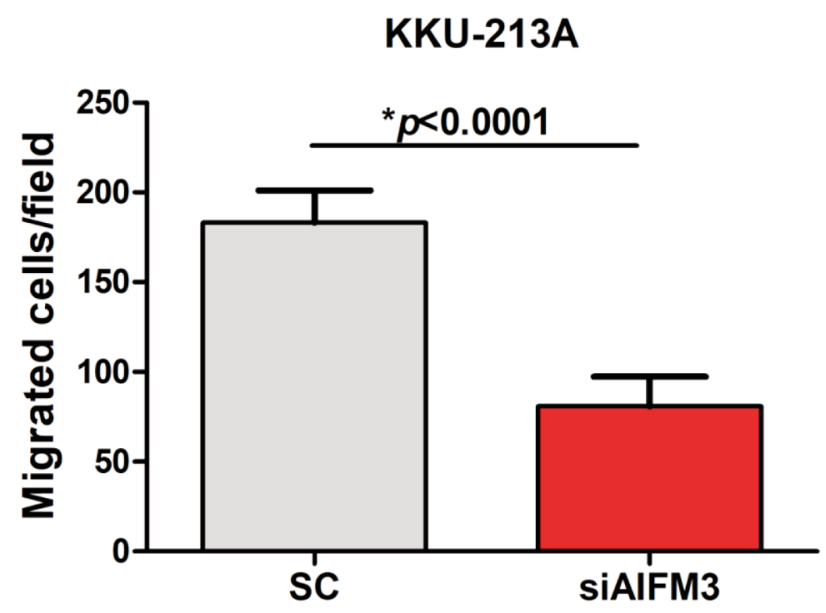

C

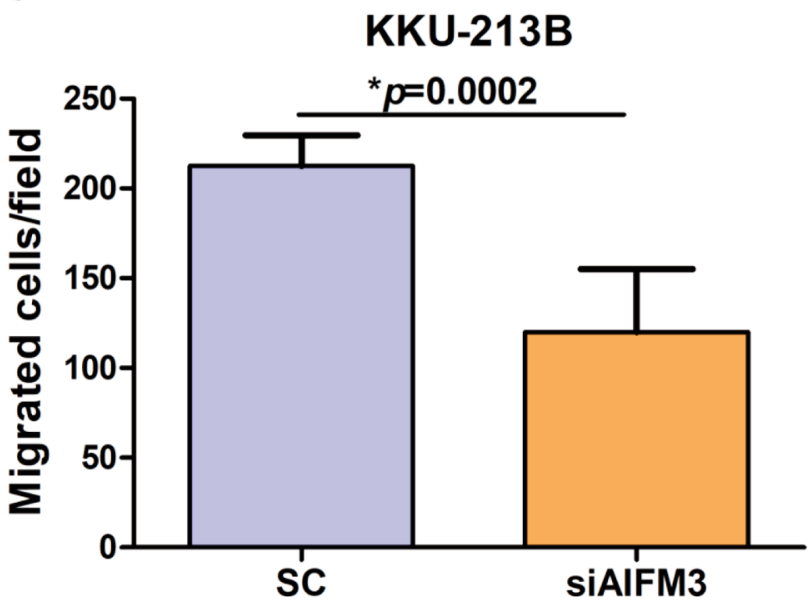

B

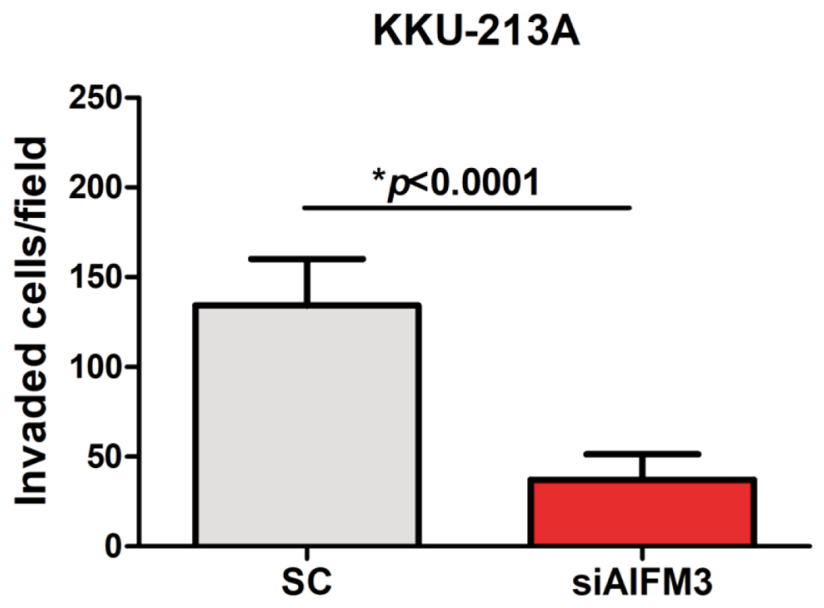

D

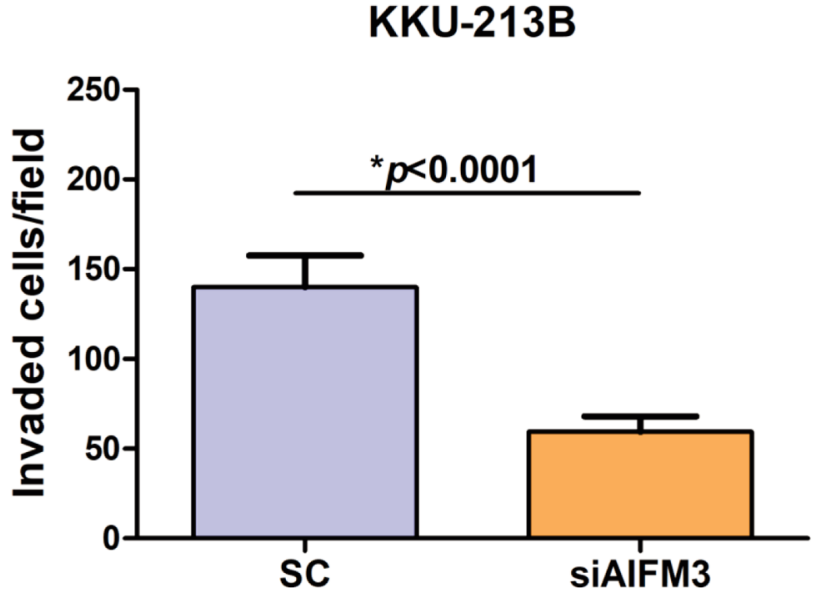

Figure 8. Effect of apoptosis-inducing factor, mitochondrion-associated 3 (AIFM3) gene silencing on migration (left panel) and invasion (right panel) activity of KKU-213A (upper panel) and KKU-213B (lower panel) cells. (A, C) Suppression of cell migration after AIFM3 gene silencing in Transwell migration assay. $(B, D)$ Suppression of cell invasion after AIFM3 gene silencing in Matrigel-invasion assay. The migrating and invading cells were counted under light microscopy with an objective lens of 10x. Six randomly selected fields for each membrane filter were counted. Values are presented as the mean $\pm S D$ from three independent experiments running in duplicate. Statistically significantly different compared to scramble control (SC) at: $p<0.001$ and $p<0.0001$.

$(p<0.0001$ and $p=0.0002$, respectively) (Figure $8 \mathrm{~A}$ and C). Cell invasion assay gave the similar results; after AIFM3 gene silencing, the number of invaded cells was significantly lower in both KKU-213A and KKU-213B cells compared with the scramble controls $(p<0.0001$ and $p<0.0001$, respectively) (Figure $8 \mathrm{~B}$ and $\mathrm{D}$ ).

Expression of AIFM3 in CCA tissues from patients with/without lymph node metastasis and its association with overall survival. The results shown above suggested potential roles of AIFM3 in migration and invasion of CCA cells. In our previous study, higher serum AIFM3 levels were significantly associated with lymph node metastasis and shorter overall survival of CCA patients (13). Here, we examined the expression of AIFM3 in CCA tissues with or without lymph node metastasis. As shown in Figures 9A and B, AIFM3 staining of CCA cells with lymph node metastasis (Figure 9A) was far stronger than that of CCA cells without lymph node metastasis (Figure 9B). H-score analysis confirmed significantly higher AIFM3 expression in CCA 
A

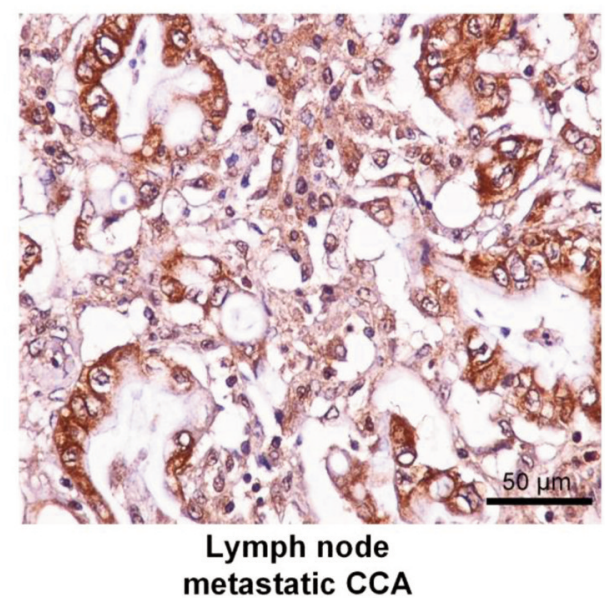

C

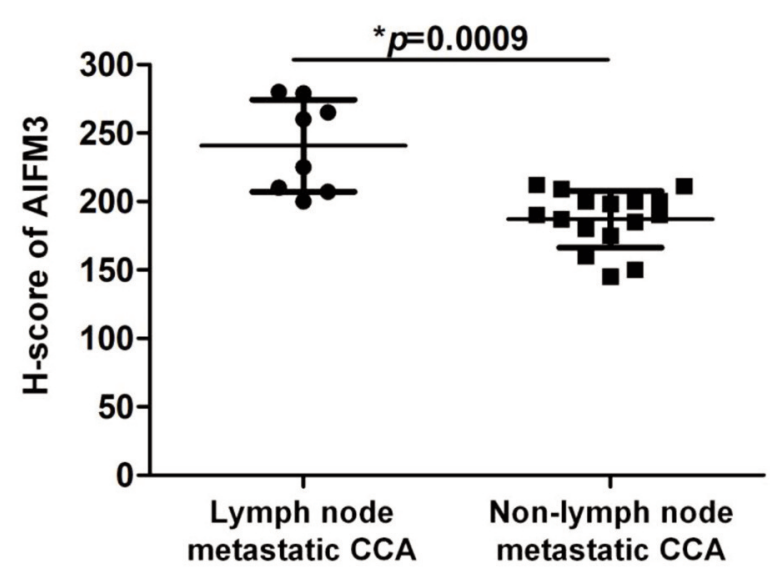

B

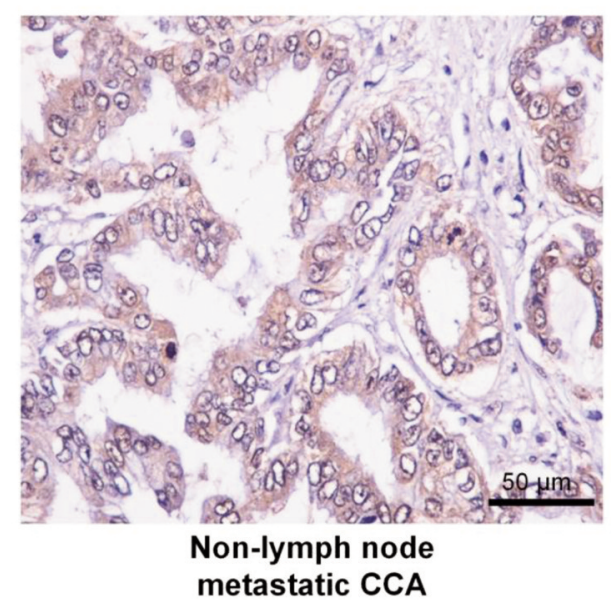

D

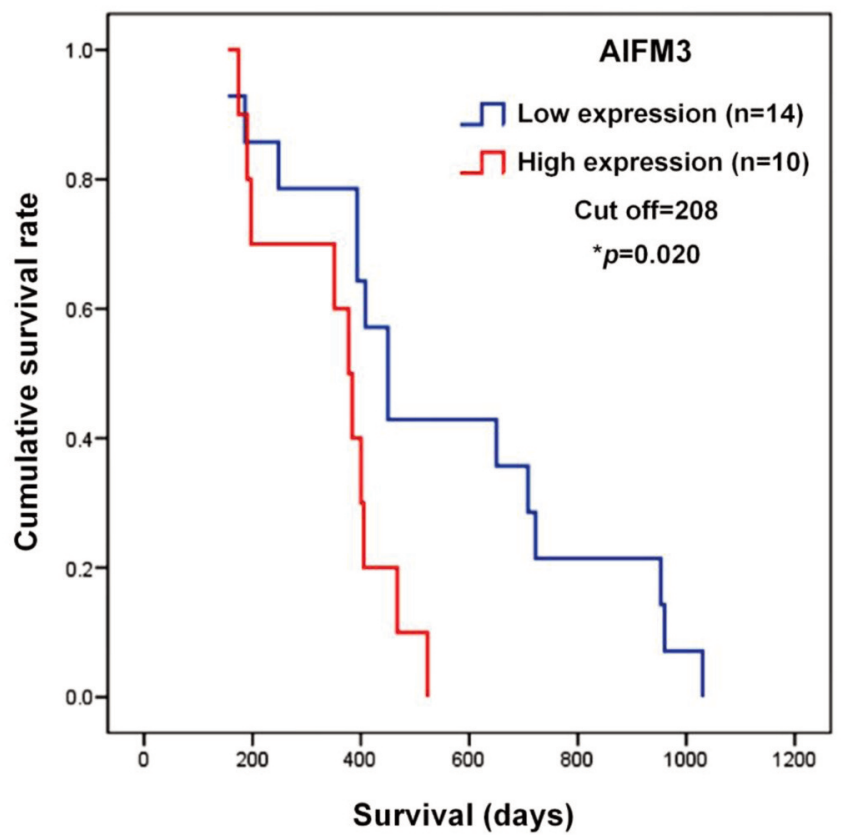

Figure 9. Representative immunohistochemical staining for apoptosis-inducing factor, mitochondrion-associated 3 (AIFM3) in human cholangiocarcinoma (CCA) tissues. (A) AIFM3 staining in lymph node metastatic CCA (magnification, x400); (B) AIFM3 staining in non-lymph node metastatic CCA; $(C)$ Comparison of $H$-score between lymph node metastatic CCA and non-lymph node metastatic CCA ( $n=24)$. Scatter plots shows the median and interquartile range of AIFM3 expression. A level of $p<0.001$ was considered statistically significant using matched-pairs $t$ test. (D) Kaplan-Meier survival curves of patients with CCA based on H-score of AIFM3. Patients with CCA were divided into low and high expression using the median value of 208 as cut off for AIFM3. The curves show overall survival of patients with CCA having low expression and high expression. The survival time was significantly different between low and high AIFM3 expression (log-rank test $p=0.020)$. *Statistical significance $(p<0.05)$.

with lymph node metastasis than in CCA without lymph node metastasis $(p=0.0009)$ (Figure 9C). Moreover, when CCA patients were divided into those low and high expression of AIFM3 using the median H-score of 208 as the cut off, the median survival time of the high AIFM3 expression group was shorter than that of the low AIFM3 expression group. When the association between AIFM3 expression and the overall survival (OS) time was compared using the Kaplan-Meier analysis, OS of CCA patients with high AIFM3 expression was significantly shorter than that of CCA patients with low AIFM3 expression (325 vs. 526 days; $p=0.020$; Figure 9D). 


\section{Discussion}

AIFM3 is expressed in many types of cells/tissues (10) and can induce apoptosis through a caspase-dependent manner $(10,11)$. AIFM3 is highly expressed in breast cancer tissues and is significantly associated with the clinical outcome of breast cancer patients (25). Our recent study revealed that higher serum AIFM3 levels are associated with lymph node metastasis and shorter overall survival of patients with CCA (13). In this study, we intended to elucidate the biological roles of AIFM3 and the related signaling pathways in CCA. For this purpose, we performed proteomic analysis of AIFM3 gene silenced and scramble-treated KKU-213A and KKU-213B cells. The results showed that the putative signaling pathways of AIFM3 involved FMNL3, PIK3CA, AKT2, SNAIL1, NFKB1, MMP2, and MMP7, all of which are key proteins in cell migration and metastasis. In particular, molecular structural analysis revealed a possible direct interaction of AIFM3 with FMNL3, a key protein of cytoskeletal regulation controlling actin. High FMNL3 expression promotes nasopharyngeal carcinoma cell metastasis though TGF- $\beta$-1-induced epithelial-mesenchymal transition (EMT) (26). Furthermore, FMNL3 promotes cell invasion in colorectal carcinoma via RhoC/FAK pathway and the actin system (27). In this study, GEPIA analysis showed positive correlation of FMNL3 mRNA expression with PIK3CA, SNAIL1, NFKB1, and MMP2. These four molecules are involved in cell migration/invasion and metastasis via the SNAIL1/EMT (28) and PI3K/AKT2 pathways (29). Phoomak et al. reported that MMP7 is in the NFKB downstream signaling pathway involved in CCA cell migration/invasion (30). In fact, AIFM3 gene silencing caused significant reduction in migration and invasion of KKU-213A and KKU213B cells. In support, it has been shown that FMNL3 inhibition caused significant suppression of cell migration and invasion of tongue squamous cell carcinoma (TSCC) (31). AIFM3 gene is located on chromosome $22 \mathrm{q} 11$, which has been implicated in metastasis and progression of colorectal, breast and prostate cancers (32). Recently, Araujo et al. reported the high copy numbers of AIFM3 were correlated with stage IIIIV medullary thyroid carcinoma (MTC). They suggested that AIFM3 is a cancer-related gene (33).

In this study, protein-chemotherapeutic drug interaction network analysis revealed that both AIFM3 and FMNL3 linked to MgATP, and MgATP is directly associated with cisplatin, doxorubicin, 5-fluorouracil, and gemcitabine that are common chemotherapeutic drugs for advanced CCA (34, 35). ATP-dependent transporter is involved in multi-drug resistance (36), and MgATP-dependent transport is associated with human multidrug resistance protein 6 (MRP6) to reduce resistance to doxorubicin (37). Possibly, the AIFM3 mediated pathway might be associated with carcinogenesis, metastasis and drug resistance via MgATP regulation. The interaction between AIFM3-FMNL3 and chemotherapeutic drug via MgATP should be explored further in vitro and in vivo for better selection of chemotherapeutic drugs for advanced stage CCA.

In this study, immunohistochemical staining demonstrated that AIFM3 protein expression in CCA tissues was significantly higher in lymph node metastatic CCA than nonlymph node metastatic CCA. Moreover, OS estimated by Kaplan-Meier was significantly shorter in patients with high AIFM3 expression than in those with low AIFM3 expression. AIFM3 was highly expressed in breast cancer tissues and was associated with lymph node metastasis and shorter OS/diseasefree survival (DFS) (25). Recently, we reported that serum AIFM3 levels were higher in CCA patients with lymph node metastasis compared to those without metastasis (13). Taking all these into account, AIFM3 expression in CCA tissues and/or serum can be useful for cancer prognosis.

\section{Conclusion}

In the present study, a new role of AIFM3 in metastasis of CCA cells was identified. AIFM3 was found to be associated with FMNL3 by STITCH prediction, and CB-Dock revealed that AIFM3 can bind FMNL3. Suppression of AIFM3 reduced migration and invasion of CCA cells. Therefore, we presumed that the signaling pathway of AIFM3 in CCA metastasis is associated to FMNL3. Moreover, AIFM3 was highly expressed in tissues from patients with CCA with lymph node metastasis and associated with shorter overall survival. The current findings demonstrate that AIFM3 could be useful in the clinical prognosis of CCA.

\section{Conflicts of Interest}

The Authors declare that they have no competing interests associated with this study.

\section{Authors' Contributions}

D. Chua-on: Conceptualization, methodology, data curation, investigation, writing-original draft. T. Proungvitaya: Conceptualization, methodology, validation and writing-review \& editing. A. Techasen: Conceptualization, methodology and validation. T. Limpaiboon: Conceptualization, methodology and validation. S. Roytrakul: Conceptualization, methodology, software and validation. D. Tummanatsakun: Methodology and investigation. N. Araki: Conceptualization, methodology and validation. S. Proungvitaya: Conceptualization, methodology, validation, writing-review \& editing, supervision and funding acquisition. All Authors have read and agreed to the published version of the manuscript.

\section{Acknowledgements}

This project was financially supported by the Thailand Research Fund through the Royal Golden Jubilee Ph.D. Program (grant no. PHD/0065/2559 to D. Chua-on) co-funded by the Khon Kaen 
University (grant no. 61003505) and the Centre of Research and Development of Medical Diagnostic Laboratories, Faculty of Associated Medical Sciences, Khon Kaen University, Khon Kaen, Thailand. The Authors express their thanks to the Cholangiocarcinoma Research Institute, Khon Kaen University, Khon Kaen, Thailand for providing cell lines and clinical specimens. The Authors are grateful to Professor Yukifumi Nawa (Tropical Diseases Research Centre, Faculty of Medicine, Khon Kaen University, Khon Kaen, Thailand), for editing the manuscript, along with the Publication Clinic of the Research Affairs.

\section{References}

1 Banales JM, Cardinale V, Carpino G, Marzioni M, Andersen JB, Invernizzi P, Lind GE, Folseraas T, Forbes SJ, Fouassier L, Geier A, Calvisi DF, Mertens JC, Trauner M, Benedetti A, Maroni L, Vaquero J, Macias RI, Raggi C, Perugorria MJ, Gaudio E, Boberg KM, Marin JJ and Alvaro D: Expert consensus document: Cholangiocarcinoma: current knowledge and future perspectives consensus statement from the European Network for the Study of Cholangiocarcinoma (ENS-CCA). Nat Rev Gastroenterol Hepatol 13(5): 261-280, 2016. PMID: 27095655. DOI: $10.1038 /$ nrgastro.2016.51

2 Tawarungruang C, Khuntikeo N, Chamadol N, Laopaiboon V, Thuanman J, Thinkhamrop K, Kelly M and Thinkhamrop B: Survival after surgery among patients with cholangiocarcinoma in Northeast Thailand according to anatomical and morphological classification. BMC Cancer 21(1): 497, 2021. PMID: 33941120. DOI: 10.1186/s12885-021-08247-Z

3 Banales JM, Marin JJG, Lamarca A, Rodrigues PM, Khan SA, Roberts LR, Cardinale V, Carpino G, Andersen JB, Braconi C, Calvisi DF, Perugorria MJ, Fabris L, Boulter L, Macias RIR, Gaudio E, Alvaro D, Gradilone SA, Strazzabosco M, Marzioni M, Coulouarn C, Fouassier L, Raggi C, Invernizzi P, Mertens JC, Moncsek A, Rizvi S, Heimbach J, Koerkamp BG, Bruix J, Forner A, Bridgewater J, Valle JW and Gores GJ: Cholangiocarcinoma 2020: the next horizon in mechanisms and management. Nat Rev Gastroenterol Hepatol 17(9): 557-588, 2020. PMID: 32606456. DOI: $10.1038 / \mathrm{s} 41575-020-0310-\mathrm{Z}$

4 Woradet S, Promthet S, Songserm N and Parkin DM: Factors affecting survival time of cholangiocarcinoma patients: a prospective study in Northeast Thailand. Asian Pac J Cancer Prev 14(3): 1623-1627, 2013. PMID: 23679246. DOI: 10.7314/ apjcp.2013.14.3.1623

5 McGee AM, Douglas DL, Liang Y, Hyder SM and Baines CP: The mitochondrial protein $\mathrm{C} 1 \mathrm{qbp}$ promotes cell proliferation, migration and resistance to cell death. Cell Cycle 10(23): 4119-4127, 2011. PMID: 22101277. DOI: 10.4161/cc.10. 23.18287

6 Commander R, Wei C, Sharma A, Mouw JK, Burton LJ, Summerbell E, Mahboubi D, Peterson RJ, Konen J, Zhou W, Du Y, Fu H, Shanmugam M and Marcus AI: Subpopulation targeting of pyruvate dehydrogenase and GLUT1 decouples metabolic heterogeneity during collective cancer cell invasion. Nat Commun 11(1): 1533, 2020. PMID: 32210228. DOI: 10.1038/s41467-02015219-7

7 Pan T, Liu J, Xu S, Yu Q, Wang H, Sun H, Wu J, Zhu Y, Zhou J and Zhu Y: ANKRD22, a novel tumor microenvironment-induced mitochondrial protein promotes metabolic reprogramming of colorectal cancer cells. Theranostics 10(2): 516-536, 2020. PMID: 31903135. DOI: $10.7150 /$ thno. 37472
8 Sanmai S, Proungvitaya T, Limpaiboon T, Chua-On D, Seubwai W, Roytrakul S, Wongkham S, Wongkham C, Somintara O, Sangkhamanon S and Proungvitaya S: Serum pyruvate dehydrogenase kinase as a prognostic marker for cholangiocarcinoma. Oncol Lett 17(6): 5275-5282, 2019. PMID: 31186744. DOI: 10.3892/ol.2019.10185

9 Truong SDA, Tummanatsakun D, Proungvitaya T, Limpaiboon T, Wongwattanakul M, Chua-On D, Roytrakul S and Proungvitaya S: Serum levels of cytokine-induced apoptosis inhibitor 1 (CIAPIN1) as a potential prognostic biomarker of cholangiocarcinoma. Diagnostics (Basel) 11(6): 1054, 2021. PMID: 34201138. DOI: 10.3390/diagnostics11061054

10 Xie Q, Lin T, Zhang Y, Zheng J and Bonanno JA: Molecular cloning and characterization of a human AIF-like gene with ability to induce apoptosis. J Biol Chem 280(20): 19673-19681, 2005. PMID: 15764604. DOI: 10.1074/jbc.M409517200

11 Yang W, Sun T, Cao J, Liu F, Tian Y and Zhu W: Downregulation of miR-210 expression inhibits proliferation, induces apoptosis and enhances radiosensitivity in hypoxic human hepatoma cells in vitro. Exp Cell Res 318(8): 944-954, 2012. PMID: 22387901. DOI: 10.1016/j.yexcr.2012.02.010

12 Chua-On D, Proungvitaya T, Techasen A, Limpaiboon T, Roytrakul S, Wongkham S, Wongkham C, Somintara O, Sungkhamanon $\mathrm{S}$ and Proungvitaya S: High expression of apoptosis-inducing factor, mitochondrion-associated 3 (AIFM3) in human cholangio-carcinoma. Tumour Biol 37(10): 1365913667, 2016. PMID: 27473083. DOI: 10.1007/s13277-0165204-x

13 Chua-On D, Proungvitaya T, Tummanatsakun D, Techasen A, Limpaiboon T, Roytrakul S, Wongkham S, Wongkham C, Somintara O, Sangkhamanon S and Proungvitaya S: Apoptosisinducing factor, mitochondrion-associated 3 (AIFM3) protein level in the sera as a prognostic marker of cholangiocarcinoma patients. Biomolecules 10(7): 1021, 2020. PMID: 32664187. DOI: $10.3390 /$ biom 10071021

14 Sripa B, Leungwattanawanit S, Nitta T, Wongkham C, Bhudhisawasdi V, Puapairoj A, Sripa C and Miwa M: Establishment and characterization of an opisthorchiasisassociated cholangiocarcinoma cell line (KKU-100). World J Gastroenterol 11(22): 3392-3397, 2005. PMID: 15948244. DOI: 10.3748/wjg.v11.i22.3392

15 Saensa-Ard S, Leuangwattanawanit S, Senggunprai L, Namwat N, Kongpetch S, Chamgramol Y, Loilome W, Khansaard W, Jusakul A, Prawan A, Pairojkul C, Khantikeo N, Yongvanit P and Kukongviriyapan V: Establishment of cholangiocarcinoma cell lines from patients in the endemic area of liver fluke infection in Thailand. Tumour Biol 39(11): 1010428317725925, 2017. PMID: 29110582. DOI: $10.1177 / 1010428317725925$

16 Maruyama M, Kobayashi N, Westerman KA, Sakaguchi M, Allain JE, Totsugawa T, Okitsu T, Fukazawa T, Weber A, Stolz DB, Leboulch P and Tanaka N: Establishment of a highly differentiated immortalized human cholangiocyte cell line with SV40T and hTERT. Transplantation 77(3): 446-451, 2004. PMID: 14966424. DOI: 10.1097/01.TP.0000110292.73873.25

17 Tummanatsakun D, Proungvitaya T, Roytrakul S and Proungvitaya S: Bioinformatic prediction of signaling pathways for apurinic/apyrimidinic endodeoxyribonuclease 1 (APEX1) and its role in cholangiocarcinoma cells. Molecules 26(9): 2587, 2021. PMID: 33946672. DOI: $10.3390 /$ molecules 26092587 
18 Bardou P, Mariette J, Escudié F, Djemiel C and Klopp C: jvenn: an interactive Venn diagram viewer. BMC Bioinformatics 15: 293, 2014. PMID: 25176396. DOI: 10.1186/1471-2105-15-293

19 Szklarczyk D, Santos A, von Mering C, Jensen LJ, Bork P and Kuhn M: STITCH 5: augmenting protein-chemical interaction networks with tissue and affinity data. Nucleic Acids Res 44(D1): D380-D384, 2016. PMID: 26590256. DOI: 10.1093/nar/ gkv1277

20 Zhu N, Hou J, Ma G and Liu J: Network pharmacology identifies the mechanisms of action of Shaoyao Gancao decoction in the treatment of osteoarthritis. Med Sci Monit 25: 6051-6073, 2019. PMID: 31409761. DOI: 10.12659/MSM.915821

21 Liu Y, Grimm M, Dai WT, Hou MC, Xiao ZX and Cao Y: CBDock: a web server for cavity detection-guided protein-ligand blind docking. Acta Pharmacol Sin 41(1): 138-144, 2020. PMID: 31263275. DOI: 10.1038/s41401-019-0228-6

22 Rizvi SM, Shakil S and Haneef M: A simple click by click protocol to perform docking: AutoDock 4.2 made easy for nonbioinformaticians. EXCLI J 12: 831-857, 2013. PMID: 2664 8810 .

23 Tang Z, Kang B, Li C, Chen T and Zhang Z: GEPIA2: an enhanced web server for large-scale expression profiling and interactive analysis. Nucleic Acids Res 47(W1): W556-W560, 2019. PMID: 31114875. DOI: $10.1093 / \mathrm{nar} / \mathrm{gkz} 430$

24 Chandrashekar DS, Bashel B, Balasubramanya SAH, Creighton CJ, Ponce-Rodriguez I, Chakravarthi BVSK and Varambally S: UALCAN: A portal for facilitating tumor subgroup gene expression and survival analyses. Neoplasia 19(8): 649-658, 2017. PMID: 28732212. DOI: 10.1016/j.neo.2017.05.002

25 Zheng A, Zhang L, Song X, Wang Y, Wei M and Jin F: Clinical implications of a novel prognostic factor AIFM3 in breast cancer patients. BMC Cancer 19(1): 451, 2019. PMID: 31088422. DOI: 10.1186/s12885-019-5659-4

26 Wu Y, Shen Z, Wang K, Ha Y, Lei H, Jia Y, Ding R, Wu D, Gan S, Li R, Luo B, Jiang H and Jie W: High FMNL3 expression promotes nasopharyngeal carcinoma cell metastasis: role in TGF- $\beta 1$-induced epithelia-to-mesenchymal transition. Sci Rep 7: 42507, 2017. PMID: 28198387. DOI: 10.1038/srep42507

27 Zeng YF, Xiao YS, Liu Y, Luo XJ, Wen LD, Liu Q and Chen M: Formin-like 3 regulates RhoC/FAK pathway and actin assembly to promote cell invasion in colorectal carcinoma. World $\mathrm{J}$ Gastroenterol 24(34): 3884-3897, 2018. PMID: 30228782. DOI: 10.3748/wjg.v24.i34.3884

28 Assani $G$ and Zhou Y: Effect of modulation of epithelialmesenchymal transition regulators Snail1 and Snail2 on cancer cell radiosensitivity by targeting of the cell cycle, cell apoptosis and cell migration/invasion. Oncol Lett 17(1): 23-30, 2019 PMID: 30655734. DOI: 10.3892/ol.2018.9636
29 Leal-Orta E, Ramirez-Ricardo J, Cortes-Reynosa P, GalindoHernandez O and Salazar EP: Role of PI3K/Akt on migration and invasion of MCF10A cells treated with extracellular vesicles from MDA-MB-231 cells stimulated with linoleic acid. J Cell Commun Signal 13(2): 235-244, 2019. PMID: 30361980. DOI: 10.1007/s12079-018-0490-2

30 Phoomak C, Vaeteewoottacharn K, Sawanyawisuth K, Seubwai W, Wongkham C, Silsirivanit A and Wongkham S: Mechanistic insights of O-GlcNAcylation that promote progression of cholangiocarcinoma cells via nuclear translocation of NF- $\varkappa \mathrm{B}$. Sci Rep 6: 27853, 2016. PMID: 27290989. DOI: 10.1038/srep27853

31 Liu J, Chen S, Chen Y, Geng N and Feng C: High expression of FMNL3 associates with cancer cell migration, invasion, and unfavorable prognosis in tongue squamous cell carcinoma. J Oral Pathol Med 48(6): 459-467, 2019. PMID: 30955218. DOI: $10.1111 /$ jop. 12857

32 Teerlink C, Nelson Q, Burt R and Cannon-Albright L: Significant evidence of linkage for a gene predisposing to colorectal cancer and multiple primary cancers on 22q11. Clin Transl Gastroenterol 5: e50, 2014. PMID: 24572700. DOI: 10.1038/ctg.2014.1

33 Araujo AN, Camacho CP, Mendes TB, Lindsey SC, Moraes L, Miyazawa M, Delcelo R, Pellegrino R, Mazzotti DR, Maciel RMB and Cerutti JM: Comprehensive assessment of copy number alterations uncovers recurrent AIFM3 and DLK1 copy gain in medullary thyroid carcinoma. Cancers (Basel) 13(2): 218, 2021. PMID: 33435319. DOI: 10.3390/cancers 13020218

34 Morise Z, Sugioka A, Tokoro T, Tanahashi Y, Okabe Y, Kagawa $\mathrm{T}$ and Takeura C: Surgery and chemotherapy for intrahepatic cholangiocarcinoma. World J Hepatol 2(2): 58-64, 2010. PMID: 21160974. DOI: $10.4254 /$ wjh.v2.i2.58

35 Yu Z, Cheng H, Zhu H, Cao M, Lu C, Bao S, Pan Y and Li Y: Salinomycin enhances doxorubicin sensitivity through reversing the epithelial-mesenchymal transition of cholangiocarcinoma cells by regulating ARK5. Braz J Med Biol Res 50(10): e6147, 2017. PMID: 28832761. DOI: 10.1590/1414-431X20176147

36 Gottesman MM, Fojo T and Bates SE: Multidrug resistance in cancer: role of ATP-dependent transporters. Nat Rev Cancer 2(1): 48-58, 2002. PMID: 11902585. DOI: 10.1038/nrc706

37 Belinsky MG, Chen ZS, Shchaveleva I, Zeng H and Kruh GD: Characterization of the drug resistance and transport properties of multidrug resistance protein 6 (MRP6, ABCC6). Cancer Res 62(21): 6172-6177, 2002. PMID: 12414644.

Received August 30, 2021

Revised November 5, 2021 Accepted November 5, 2021 